\title{
MEDIA PEMBELAJARAN WARTOP (WAYANG KARAKTER TOKOH PAHLAWAN) UNTUK MENUMBUHKAN JIWA NASIONALISME MAHASISWA IKIP BUDI UTOMO MALANG
}

\author{
Puspita Pebri Setian \\ Prodi Pendidikan Sejarah dan Sosiologi, IKIP Budi Utomo Malang \\ puspitapebri@gmail.com \\ Trio Andi Cahyono \\ Prodi Pendidikan Ekonomi, IKIP Budi Utomo Malang
}

\begin{abstract}
Wayang Karakter Tokoh Pahlawan (in English: Wayang of Hero Figures)(WARTOP) in the Department of History and Sociology is a media that does not yet exist and needs to be developed. This study aims to describe the design of WARTOP development with ADDIE (analyze, design, development, implementation, evaluation) model in the Indonesian Contemporary History course for the 5th semester students in IKIP Budi Utomo Malang 2016/2017 academic year as well as being an effective, innovative, creative historical media, and fun in cultivating and enhancing a sense of nationalism. In addition, this study aims to determine the quality of WARTOP development outcomes according to expert reviews, individual trials, small group trials, and field trials. The subject of validation consists of a course content expert, a learning media expert, an instructional designer, 7 students for individual trials, 14 students for small group trials, and 40 students for field trials. Data collection method used is document recording and questionnaire. The analysis technique used is quantitative descriptive analysis technique. The result of this research is a developed WARTOP based on storyboard design. The validity of WARTOP is: (1) according to expert review of the content of the course, WARTOP indicates good category (92\%), (2) according to expert review of the instructional design, WARTOP indicates good category (88\%), (3) according to expert review of the learning media, WARTOP indicates good category 86\%), (4) the results of the individual trials shows good category (83\%), (5) small group trials shows good category (82\%), (6) field trials shows good category (81\%). Thus, WARTOP does not need to be revised and can be used for further research.
\end{abstract}

Abstrak: $\quad$ Wayang Karakter Tokoh Pahlawan (WARTOP) di Jurusan Sejarah dan Sosiologi adalah sebuah media yang belum ada dan perlu dikembangkan. Penelitian ini bertujuan untuk mendeskripsikan desain pengembangan WARTOP dengan model ADDIE (analyze, design, development, implementation, evaluation) pada mata kuliah Sejarah Kontemporer Indonesia semester 5 di IKIP Budi Utomo Malang tahun ajaran 2016/2017 serta menjadi media sejarah yang efektif, inovatif, kreatif, dan menyenangkan dalam menumbuhkan dan meningkatkan rasa nasionalisme. Di samping itu, penelitian ini bertujuan untuk mengetahui kualitas hasil pengembangan WARTOP menurut review ahli, uji coba perorangan, uji coba kelompok kecil, dan uji coba lapangan. Adapun subjek validasi terdiri dari seorang ahli isi mata kuliah, seorang ahli media pembelajaran, seorang ahli desain pembelajaran, 7 mahasiswa untuk uji coba perorangan, 14 mahasiswa untuk uji coba kelompok kecil, dan 40 mahasiswa untuk uji coba lapangan. Metode pengumpulan data yang digunakan adalah pencatatan dokumen dan angket. Teknik analisis yang digunakan adalah teknik analisis deskriptif kuantitatif. Hasil penelitian ini adalah sebuah WARTOP yang dikembangkan berdasarkan desain (storyboard) yang dirancang. Validitas WARTOP adalah: (1) menurut review ahli isi mata kuliah menunjukkan kategori baik $(92 \%)$, (2) menurut review ahli desain pembelajaran berada pada kategori baik (88\%), (3) menurut review ahli media pembelajaran menunjukkan kategori baik (86\%), (4) berdasarkan hasil uji coba perorangan menunjukkan kategori baik (83\%), (5) berdasarkan uji coba kelompok kecil berada pada kategori baik (82\%), (6) berdasarkan uji coba lapangan menunjukkan kategori baik (81\%). Dengan demikian WARTOP ini tidak perlu di revisi dan dapat digunakan untuk penelitian lebih lanjut.

Kata Kunci: $\quad$ media pembelajaran, wayang karakter tokoh pahlawan, WARTOP, model ADDIE

\section{PENDAHULUAN}

Peraturan Pemerintah Nomor 32 Tahun 2013 tentang Perubahan atas Peraturan Pemerintah Nomor 19 Tahun 2005 tentang Standar Nasional Pendidikan. Proses Pembelajaran pada satuan pendidikan diselenggarakan secara interaktif, inspiratif, menyenangkan, menantang, memotivasi peserta didik untuk berpartisipasi aktif, serta memberikan ruang yang cukup bagi prakarsa, kreativitas, dan kemandirian sesuai dengan bakat, minat, dan perkembangan fisik serta psikologis peserta didik. Untuk itu setiap satuan pendidikan 
melakukan perencanaan pembelajaran, pelaksanaan proses pembelajaran serta penilaian proses pembelajaran untuk meningkatkan efisiensi dan efektivitas ketercapaian kompetensi lulusan.

Proses belajar mengajar pada hakikatnya adalah proses komunikasi, yaitu proses penyampaian pesan dari sumber pesan melalui media tertentu ke penerima pesan. Pesan, sumber pesan, media, dan penerima pesan adalah komponen-komponen proses komunikasi. Dalam kegiatan pembelajaran pesan yang akan dikomunikasikan adalah isi ajaran atau materi yang ditetapkan berdasarkan kurikulum yang berlaku. Berbagai macam sumber pesan diantaranya pengajar, peserta didik, orang lain, penulis buku, produser media dan sebagainya.

Media pembelajaran atau media pendidikan merupakan saluran pesan tersebut sedangkan penerima pesannya adalah peserta didik bahkan pengajar itu sendiri. Sebuah pesan dituangkan oleh pengajar atau sumber lain ke dalam simbol-simbol komunikasi baik simbol verbal (kata-kata lisan ataupun tertulis) maupun simbol non-verbal atau visual. Proses penuangan pesan ke dalam simbolsimbol komunikasi itu disebut encoding. Dalam proses penyampaian pesan tersebut, pengajar sebagai fasilitator dapat menggunakan media pembelajaran.

Salah satu fungsi utama media pembelajaran adalah sebagai alat bantu mengajar yang turut mempengaruhi iklim, kondisi, dan lingkungan belajaryang di tata dan di ciptakan oleh guru (Arsyad, 2011). Maka dari itu, pemilihan media dalam proses belajar mengajar memiliki banyak jenisnya tinggal menyesuaikan antara tujuan pembelajaran dengan karakteristik media tersebut. Beragam jenis media yang ada tersebut mengalami perkembangan yang pesat terutama dari segi penyajian yang semakin hari semakin inovatif. Dewasa ini pengembangan media pembelajaran disesusaikan dengan kondisi pengajar dan peserta belajar, terutama respon dan kebutuhan peserta belajar. Peran media tidak hanya sebagai alat bantu menyampaikan pesan pengajar kepada siswa saja akan tetapi media pembelajaran diharapkan mampu menarik minat peserta belajar untuk mau memahami lebih jauh tentang isi materi yang disampaikan oleh guru atau pengajar.

WARTOP Indonesia diharapkan menjadi media pembelajaran sejarah yang efektif, inovatif, kreatif dan menyenangkan sehingga memberikan kesan tersendiri bagi mahasiswa dan dosen dalam proses pembelajaran sehingga dapat memajukan pendidikan Indonesia menjadi lebih baik. Berdasarkan pemikiran diatas maka Indonesia dapat dijadikan media pembelajaran sejarah yang efektif, inovatif, kreatif dan menyenangkan.

Beragam gaya dan konsep baru dari wayang membuat wayang lebih banyak karakter yang muncul, tidak hanya tokoh-tokoh pewayangan jawa yang melegenda akan tetapi karakter orang bahkan sosok tokoh-tokoh, tak terkecuali wayang karakter tokoh pahlawan Indonesia. Wayang dengan karakter tokoh pahlawan Indonesia menjadi satu media pembelajaran sejarah yang efektif, inovatif, kreatif dan menyenangkan.

Secara umum, media pembelajaran merupakan alat bantu proses belajar mengajar. Segala sesuatu yang dapat dipergunakan untuk merangsang pikiran, perasaan, perhatian dan kemampuan atau ketrampilan pebelajar sehingga dapat mendorong terjadinya proses belajar. Penggunaan WARTOP atau wayang dengan karakter tokoh pahlawan Indonesia seperti Ir. Soekarno, Moh. Hatta, dan tokoh pahlawan lainnya ataupun tokoh yang terlibat dalam peristiwa bersejarah merupakan media pembelajran sejarah yang inovatif terutama dalam menggambarkan situasi dan rekam adegan dalam peristiwa-peristiwa bersejarah di Indonesia seperti peristiwa Proklamasi Kemerdekaan Indonesia pada tanggal 17 Agustus 1945. WARTOP menjadi media pembelajaran merupakan alat bantu mengajar yang turut mempengaruhi iklim, kondisi, dan lingkungan belajar yang di tata dan di ciptakan oleh guru atau dosen yang dapat digunakan dalam matakuliah Sejarah Kontemporer Indonesia pada mahasiswa Pendidikan Sejarah dan Sosiologi FPISH IKIP Budi Utomo Malang.

Berdasarkan uraian di atas, untuk membantu mahasiswa dalam memahami mata kuliah Sejarah Kontemporer Indonesia, maka dipandang sangat perlu dikembangkan sebuah media pembelajaran WARTOP. Olehkarenaitu, penelitian pengembangan ini mengambil judul "Pengembangan Media Pembelajaran WARTOP Pada Mahasiswa Prodi Pendidikan Sejarah dan Sosiologi FPISH IKIP Budi Utomo Malang. 


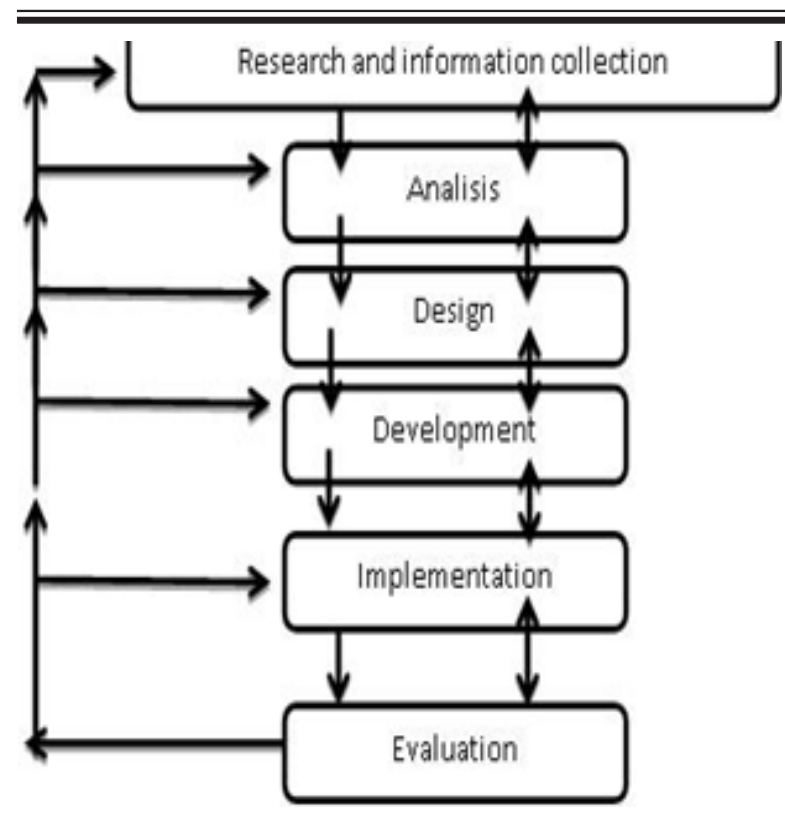

Bagan 2.1. Model Penelitian dan Pengembangan Media Pembelajaran WARTOP

Rumusan masalah penelitian ini adalah: (1) Bagaimana media pembelajaran WARTOP sebagai media pembelajaran pilihan dalam mata kuliah Sejarah Kontemporer Indonesia mahasiswa jurusan pendidikan sejarah dan sosiologi angkatan 2014? (2) Bagaimana media pembelajaran WARTOP sebagai media pembelajaran sejarah yang efektif, inovatif, kreatif dan menyenangkan dapat menumbuhkan rasa nasionalisme mahasiswa dalam matakuliah Sejarah Kontemporer Indonesia mahasiswa pendidikan sejarah dan sosiologi angkatan tahun 2014? Untuk memecahkan kedua masalah tersebut maka dilakukan penelitian pengembangan dengan model ADDIE yang menghasilkan media pembelajaran WARTOP. Selanjutnya dilakukan validasi terhadap produk yang dihasilkan

\section{METODE}

Penelitian ini menggunakan Research And Development (Penelitian dan Pengembangan). Menurut Borg \& Gall (1983) dalam Setyosari (2010: 194) penelitian pengembangan adalah suatu proses yang dipakai untuk mengembangkan dan memvalidasi produk pendidikan. Setiap tahapan dalam penelitian dan pengembangan dilakukan dengan mengacu pada tahapan sebelumnya. Penelitian pengembangan pendidikan meliputi proses pengembangan dan validasi produk. Melalui penelitian pengembangan peneliti berusaha untuk mengembangkan suatu produk yang efektif digunakan dalam pembelajaran.

Metode pengembangan yang digunakan dalam pengembangan bahan ajar ini adalah model ADDIE yang merupakan salah satu model desain pembelajaran. Model pengembangan ADDIE merupakan model desain pembelajaran yang berlandasan pada pendekatan sistem yang efektif dan efisien serta prosesnya yang bersifat interaktif yakni hasil evaluasi setiap fase dapat membawa pengembangan pembelajaran ke fase selanjutnya. Hasil akhir dari suatu fase merupakan produk awal bagi fase berikutnya. Model ini terdiri atas 5 fase atau tahap utama yaitu analyze (analisis), design (desain), develop (pengembangan), implement (implementasi), dan evaluate (evaluasi) (Ibrahim, 2011). Bagan model pengembangan yang digunakan dalam penelitian dan pengembangan media pembelajaran WARTOP dapat dilihat di Bagan 2.1.

Subjek pada penelitian ini adalah satu orang ahli isi mata pelajaran, satu orang ahli desain pembelajaran, satu orang ahli media pembelajaran, tujuh orang untuk uji perorangan, empat belas orang untuk uji kelompok kecil, dan empat puluh orang untuk uji lapangan. Ahli isi mata pelajaran dalam penelitian pengembangan ini adalah Dra. Amanah Agustin, M.Pd. Ahli desain pembelajaran adalah Dr. Rusdi, M.Hum. yang merupakan dosen Program Pendidikan Sejarah dan Sosiologi IKIP Budi Utomo Malang dan ahli media pembelajaran merupakan dosen di UNESA adalah Dr. Nasution, M.Ed., Ph.D. Subjek coba pada uji perorangan, uji kelompok kecil, dan uji lapangan adalah mahasiswa kelas A angkatan 2014 IKIP Budi Utomo Malang.

Metode pengumpulan data yang digunakan pada penelitian ini adalah metode pencatatan dokumen dan angket. Metode pencatatan dokumen menggunakan instrument pengumpulan data berupa agenda kerja. Metode angket menggunakan instrument pengumpulan data berupa kuesioner. Kuesioner digunakan untuk mengumpulkan hasil review ahli isi mata pelajaran, review ahli desain pembelajaran, review ahli media pemblajaran, siswa saat uji perorangan, uji kelompok kecil, dan uji lapangan. Jenis data yang didapat dari penelitian ini adalah data kuantitatif. Data yang telah terkumpul 
kemudian dianalisis dengan teknik analisis deskriptif kuantitatif

\section{HASIL DAN PEMBAHASAN}

Desain pengembangan WARTOP telah dilakukan dengan metode pencatatan dokumen. Pencatatan dokumen dilakukan dengan mencatat tahap-tahap yang telah dilakukan sesuai dengan prosedur pengem-bangan. Berdasarkan pencatatan dokumen yang telah dilakukan, menghasilkan laporan pengembangan produk. Dalam laporan pengembangan produk, terdapat bagian yang menjelaskan desain pengembangan WARTOP.

Produk pengembangan WARTOP diserahkan kepada seorang ahli isi mata kuliah Sejarah Kontemporer Indonesia di IKIP Budi Utomo Malang Dra. Amanah Agustin, M.Pd. untuk mendapatkan penilaian dan masukan. Instrumen yang diguanakan untuk validasi ini adalah kuesioner. Metode pengumpulan data yang digunakan adalah metode angket. Berikut dipaparkan hasil penilaian ahli isi mata kuliah Sejarah Kontemporer Indonesia terhadap produk pengembangan melalui metode angket.

Tabel 2.1. Hasil Penilaian Ahli Isi Mata Pelajaran

\begin{tabular}{|l|l|l|}
\hline No & Aspek yang dinilai & Skor \\
\hline 1. & Kejelasan indikator & 5 \\
\hline 2. & $\begin{array}{l}\text { Kejelasan indikator dengan } \\
\text { materi }\end{array}$ & 5 \\
\hline 3. & Kejelasan tujuan pembelajaran & 5 \\
\hline 4. & Kejelasan materi dengan tujuan & 5 \\
\hline 5. & Kejelasan penyajian materi & 4 \\
\hline 6. & Kelengkapan materi materi & 5 \\
\hline 7. & $\begin{array}{l}\text { Kesesuaian konsep } \\
\text { pelajaran }\end{array}$ & 4 \\
\hline 8. & Kesesuaian evaluasi dan tujuan & 5 \\
\hline 9. & Kejelasan soal/tes & 4 \\
\hline 10. & $\begin{array}{l}\text { Kesesuaian isi mata pelajaran } \\
\text { dengan waktu yang disediakan }\end{array}$ & 4 \\
\hline & Jumlah & 46 \\
\hline
\end{tabular}

Berdasarkan penilaian ahli mata kuliah Sejarah Kontemporer Indonesia sebagaimana tercantum dalam tabel 2.1, maka dapat dihitung persentase tingkat pencapaian WARTOP mata Kuliah Sejarah Kontemporer Indonesia mahasiswa angkatan 2014 semester 5, yaitu sebagai berikut.

$$
\begin{aligned}
\text { Persentase }= & \left(\sum(\text { jawaban } \times \text { bobot tiap pilihan }) /(\mathrm{n} \times\right. \\
& \text { bobot tertinggi }) \times 100 \% \\
= & 46 /(10 \times 5) \times 100 \%=92 \%
\end{aligned}
$$

Persentase pencapaian WARTOP adalah 92\%, berartiWARTOPiniberadapadakategorisangatbaik, sehingga multimedia interaktif tidak perlu direvisi. Namum, ahli isi mata kuliah juga memberikan saran agar materi dikembangkan lagi dan media wayang ditambah lagi guna pengembangan pada materimateri yang lainnya. Sesuai dengan masukan ahli isi, guna penyempurnaan produk pengembangan, materi WARTOP sudah dikembangkan dan media wayang sudah ditambah lagi.

Menurut hasil penilaian ahli isi mata kuliah didapat bahwa kisaran nilai berada pada skor 4 (baik) dan 5 (sangat baik). Menurut ahli mata isi kuliah, kejelasan penyajian materi, kesesuaian konsep materi pelajaran, kejelasan tujuan, kesesuaian isi pelajaran dengan waktu yang disediakan masih menunjukkan nilai baik. Namun WARTOP ini sudah menunjukkan nilai sangat baik pada bagian kejelasan indikator, kesesuaian indikator dengan materi, kejelasan tujuan pembelajaran, kesesuaian materi dengan tujuan, kelengkapan materi, dan kesesuaian evaluasi dan tujuan, sehingga media WARTOP dapat dikatakan valid menurut ahli isi mata pelajaran.

Setelah melakukan revisi media sesuai masukan ahli isi mata pelajaran, langkah selanjutnya adalah review ahli desain pembelajaran. Pada review ini yang menjadi ahli desain pembelajaran adalah Dr. Rusdi, M.Hum Instrumen yang diguanakan untuk validasi ini adalah kuesioner. Metode pengumpulan data yang digunakan adalah metode angket. Berikut dipaparkan hasil penilaian ahli desain pembelajaran 
terhadap produk pengembangan melalui metode angket.

Tabel 2. Hasil Penilaian Ahli Desain Mata Pelajaran

\begin{tabular}{|l|l|l|}
\hline No & Aspek yang dinilai & Skor \\
\hline 1. & $\begin{array}{l}\text { Kemenarikan tampilan fisik } \\
\text { WARTOP }\end{array}$ & 5 \\
\hline 2. & Keseimbangan tata warna & 4 \\
\hline 3. & $\begin{array}{l}\text { Kejelasan petunjuk penggunaan } \\
\text { WARTOP }\end{array}$ & 5 \\
\hline 4. & $\begin{array}{l}\text { Ketepatan penggunaan desain } \\
\text { penyajian materi }\end{array}$ & 4 \\
\hline 5. & Kejelasan paparan materi & 4 \\
\hline 6. & Kesesuaian alur cerita & 4 \\
\hline 7. & $\begin{array}{l}\text { Kesesuaian teks certa dengan tokoh } \\
\text { wayang pahlawan }\end{array}$ & 4 \\
\hline 8. & $\begin{array}{l}\text { Kesesuaian durasi waktu dan } \\
\text { karakteristik sasaran }\end{array}$ & 4 \\
\hline 9. & $\begin{array}{l}\text { Kesesuaian penempatan bagian- } \\
\text { bagian pada wayang }\end{array}$ & 5 \\
\hline 10. & Kesesuaian evaluasi dan tujuan & 5 \\
\hline & Jumlah & 44 \\
\hline
\end{tabular}

Berdasarkan penilaian dari ahli desain pembelajaran sebagaimana tercantum dalam tabel di atas maka dapat dihitung persentase tingkat pencapaian WARTOP yaitu sebagai berikut.

$$
\begin{aligned}
\text { Persentase }= & \left(\sum(\text { jawaban } \times \text { bobot tiap pilihan }) /(\mathrm{n} \times\right. \\
& \text { bobot tertinggi }) \times 100 \% \\
= & 44 /(10 \times 5) \times 100 \%=88 \%
\end{aligned}
$$

Persentase pencapaian WARTOP adalah 88\%. Ini berarti, WARTOP ini berada pada kategori baik sehingga WARTOP tidak perlu direvisi. Pada bagian masukan, saran, dan komentar, ahli desain memberikan beberapa masukan. Untuk proses penyempurnaan produk pengembangan, WARTOP diperbaiki sesuai masukan, saran, dan komentar yang diberikan. Adapun masukan, saran, dan komentar adalah sebagai berikut: a. penggunaan media sebagai alternatif dalam pembelajaran sangat bagus sekali, akan tetapi tokoh pahlawan di perbanyak agar mahasiswa mengetahui sosok/figur pahlawan tersebut;

b. di bawah wayang perlu ditulis nama tokoh;

c. sebelum wayang di mainkan sebaiknya mahasiswa di beirikan skrip cerita yang akan dilakukan;

d. mahasiswa IKIP Budi Utomo yang bukan mayoritas orang Jawa, mereka pasti baru mengetahui dan melihat pertunjukan wayang, alangkah lebih baiknya mereka diberi pengantar terkait dengan wayang tersebut.

Menurut hasil penilaian yang diberikan oleh ahli desain pembelajaran, didapat bahwa kisaran nilai berada pada skor 4 (baik) dan 5 (sangat baik). Ahli desain pembelajaran menilai bahwa keseimbangan tata warna memperoleh skor 4 (baik) ini dikarenakan produk WARTOP menggunakan satu warna yang dominan. Pada ketepatan penggunaan desain penyajian materi, kejelasan paparan materi, kesesuaian alur cerita, kesesuaian teks cerita dengan tokoh wayang pahlawan, kesesuaian durasi waktu dan karakteristik sasaran masih mendapat-kan nilai baik. Namun pada bagian lain sudah mendapatkan nilai sangat baik, sehingga media WARTOP valid menurut ahli desain pembelajaran.

Setelah direvisi, produk berupa WARTOP diserahkan kepada ahli media pembelajaran atas yaitu Dr. Nasution, M.Ed., P.hD untuk mendapat penilaian dan masukan. Berikut ini merupakan hasil penilaian dari ahli media pembelajaran.

\section{Tabel 2.3. Hasil Penilaian Ahli Media Mata Pelajaran}

\begin{tabular}{|l|l|l|}
\hline No & Aspek yang dinilai & Skor \\
\hline 1. & Kesesuaian media dan tujuan & 5 \\
\hline 2. & $\begin{array}{l}\text { Kesesuaian media dengan peserta } \\
\text { didik }\end{array}$ & 4 \\
\hline 3. & Kejelasan tampilan WARTOP & 4 \\
\hline 4. & $\begin{array}{l}\text { Nilai estetika penggunaan tokoh- } \\
\text { tokoh WARTOP }\end{array}$ & 5 \\
\hline 5. & Kualitas tampilan WARTOP & 4 \\
\hline
\end{tabular}




\begin{tabular}{|l|l|l|}
\hline 6. & $\begin{array}{l}\text { Kesesuaian adegan WARTOP } \\
\text { dengan teks }\end{array}$ & 4 \\
\hline 7. & $\begin{array}{l}\text { Ketepatan cerita sejarah dengan } \\
\text { permainan WARTOP }\end{array}$ & 5 \\
\hline 8. & $\begin{array}{l}\text { Kualitas suara seorang dalang } \\
\text { WARTOP }\end{array}$ & 4 \\
\hline 9. & Kelancaran memainkan WARTOP & 4 \\
\hline 10. & Kelancaran dalam alur cerita & 5 \\
\hline 11 & Keseimbangan warna WARTOP & 4 \\
\hline 12 & $\begin{array}{l}\text { Kesatuan media WARTOP dengan } \\
\text { yang memainkankannya }\end{array}$ & 4 \\
\hline & Jumlah & 52 \\
\hline
\end{tabular}

Berdasarkan penilaian dari ahli media pembelajaran sebagaimana tercantum dalam tabel di atas maka dapat dihitung persentase tingkat pencapaian media WARTOP yaitu sebagai berikut Persentase $=(\Sigma($ jawaban $\mathrm{x}$ bobot tiap pilihan $) /(\mathrm{n} \mathrm{x}$ bobot tertinggi) $\times 100 \%$ $=52 /(10 \times 5) \times 100 \%=86,67 \%$

Persentase pencapaian multimedia interaktif adalah $86,67 \%$. Ini berarti, WARTOP berada pada kategori baik, sehingga WARTOP tidak perlu direvisi. Pada bagian masukan, saran dan komentar, ahli media pembelajaran memberikan masukan agar skrip cerita wayang agar diperbaiki katakata yang salah. Guna penyempurnaan produk pengembangan WARTOP direvisi sesuai dengan masukan, saran, dan komentar yang diberikan.

Menurut hasil penilaian dari ahli media pembelajaran, didapat bahwa kisaran nilai berada pada skor 4 (baik) dan 5 (sangat baik). Kesesuaian media dengan peserta didik, kejelasan tampilan WARTOP, Kualitas tampilan WARTOP, kesesuaian adegan wayang dengan teks, kualitas suara seorang dalang wayang, kelancaran memainkan wayang, keseimbangan warna WARTOP, kesatuan media wayang dengan yang memainkan wayang mendapatkan skor 4 (baik). Namun pada butir Kesesuaian media dan tujuan, nilai estetika penggunaan tokoh-tokoh wayang pahlawan, ketepatan cerita sejarah dengan permainan wayang, kelancaran dalam alur cerita ahli media pembelajaran memberikan skor 5 (sangat baik), sehingga WARTOP ini valid menurut ahli media pembelajaran.

Setelah WARTOP direvisi sesuai masukan ahli media pembelajaran, WARTOP dilanjutkan pada uji perorangan. Subyek uji perorangan adalah tujuh orang mahasiswa Jurusan Pendidikan Sejarah dan Sosiologi IKIP Budi Utomo Malang Angkatan 2014. Ketujuh mahasiswa tersebut terdiri atas dua orang berprestasi belajar tinggi, tiga orang berprestasi belajar sedang, dan dua orang berprestasi belajar rendah. Berdasarkan analisis penilaian dari uji perorangan, dapat dihitung persentase tingkat pencapaian media sebagai berikut.

$$
\begin{array}{ccccc}
\text { Persentase }= & \mathrm{F} & : & \mathrm{N} \\
=581 \% & : & 7 & \\
= & 83 \% & & &
\end{array}
$$

Persentase WARTOP adalah 83\%. Ini berarti, WARTOP berada pada kategori baik, sehingga WARTOP tidak perlu direvisi.

Setelah uji perorangan, dilanjutkan pada uji kelompok kecil. Subyek uji kelompok kecil adalah empat belas mahasiswa Jurusan Pendidikan Sejarah dan Sosiologi IKIP Budi Utomo Malang Angkatan 2014. Keempatbelas orang siswa tersebut terdiri atas lima orang berprestasi belajar tinggi, empat orang berprestasi belajar sedang, dan lima orang berprestasi belajar rendah. Berdasarkan analisis penilaian dari uji kelompok kecil, dapat dihitung persentase tingkat pencapaian media sebagai berikut

$$
\begin{aligned}
& \text { Persentase }=F \quad: \quad \mathrm{N} \\
& \quad=1148 \%: \quad: 14 \\
& \quad=82 \%
\end{aligned}
$$

Persentase pencapaian WARTOP adalah 82\%. Ini berarti WARTOP berada pada kategori baik, sehingga WARTOP tidak perlu direvisi.

Setelah uji kelompok kecil, langkah selanjutnya adalah uji lapangan. Pada uji lapangan dilakukan dengan subjek coba empat puluh mahasiswa Jurusan 
Pendidikan Sejarah dan Sosiologi IKIP Budi Utomo Malang Angkatan 2014. Metode pengum-pulan data yang digunakan adalah dengan angket. Selanjutnya berdasarkan hasil dari uji lapangan, dapat dihitung persentase tingkat pencapaian media sebagai berikut.

$$
\begin{array}{lllll}
\text { Persentase }= & F & : & \mathrm{N} \\
= & 3240 \% & : & 7 & \\
=81 \% & & &
\end{array}
$$

Persentase WARTOP adalah 83\%. Ini berarti, WARTOP berada pada kategori baik, sehingga WARTOP tidak perlu direvisi.

Berdasarkan penilaian yang telah dilakukan maka dapat dihasilkan sebuah WARTOP yang teruji validitasnya berdasarkan ahli isi mata kuliah, ahli desain pembelajaran, ahli media pembelajaran, uji coba perorangan, uji coba kelompok kecil, dan uji coba lapangan. Secara umum WARTOP ini tidak perlu direvisi dan siap digunakan untuk penelitian lebih lanjut.

\section{SIMPULAN}

Berdasarkan hasil dan pembahasan, didapat dua buah simpulan. Adapun simpulan dari penelitian ini dipaparkan sebagai berikut.

Pertama, desain pengembangan WARTOP menghasilkan storyboard. Desain ini digunakan untuk mengembangkan sebuah produk WARTOP pada mata kuliah Sejarah Kontemporer Indonesia semester 5 di Jurusan Pendidikan Sejarah dan Sosiologi IKIP Budi Utomo Malang Angkatan 2014.

Kedua, validitas WARTOP adalah

1. menurut review ahli isi mata pelajaran menunjukkan kategori sangat baik (92\%);

2. menurut review ahli desain pembelajaran berada pada kategori baik ( $88 \%)$;

3. menurut review ahli media pembelajaran menunjukkan kategori baik (86,\%);

4. berdasarkan uji coba perorangan menunjukkan kategori baik (83\%);

5. berdasarkan uji coba kelompok kecil berada pada kategori baik (82\%);

6. berdasarkan uji coba lapangan menunjukkan kategori baik (81\%).
Dengan demikian WARTOP ini tidak perlu direvisi dan digunakan untuk penelitian lebih lanjut.

Berdasarkan simpulan, adapun saran yang disampaikan berkaitan dengan pengembangan WARTOP ini adalah, mengingat WARTOP telah tervalidasi, disarankan bagi mahasiswa untuk menggunakan WARTOP ini sebagai salah satu sumber belajar; dan mahasiswa juga dapat memiliki WARTOP ini secara mandiri, sehingga mahasiswa dapat mempelajarinya kapan pun dan dimana pun. Saran bagi dosen adalah agar WARTOP yang telah tervalidasi, diterapkan dalam proses pembelajaran sehingga dapat mencapai tujuan pembelajaran secara efektif dan efisien.

WARTOP yang telah teruji validitasnya akan memberikan poin positif jika sewaktu-waktu kampus didatangi tim monitoring. Dengan demikian, saran bagi pimpinan perguruan tinggi agar menyimpan WARTOP ini dengan baik, sebagai salah satu koleksi media pembelajaran di kampus. Penelitian ini telah menghasilkan WARTOP dengan model ADDIE dengan kategori baik. Setelah penelitian ini menghasilkan sebuah WARTOP yang teruji validitasnya, diharapkan bagi peneliti lain melakukan penelitian eksperimen untuk mengetahui efektivitas WARTOP ini dalam meningkatkan prestasi belajar.

Pada

\section{REFERENSI}

Arif, M. (2008). Desain Pembelajaran Sejarah berbasis Hiperteks dalam Sejarah dalam Keberagaman (Penghormatan kepada Prof. Dr.Helius Sjamsuddin, Ph.D, M.A). Jurdik Sejarah UPI: Bandung.

Arsyad, Azhar. (2011). Media Pembelajaran. Jakarta: PT Raja Grafindo Persada.

Bogdan, R and Taylor. (1982). Qualitative Research for Education: An Introducyion to Theory and Methode. Boston: Allyn and Bacon

Hasan, S.H.. (1999). Pendidikan Sejarah untuk Membangun Manusia Baru Indonesia, dalam Mimbar Pendidikan, Nomor 2 Tahun XVIII, Bandung IKIP Bandung, hlm.4-11.

Hasan, Said Hamid. (2012). Pendidikan Sejarah Indonesia: Isu dan dalam Ide dan Pembelajaran. Bandung: Rizki Ofset 
Media Pembelajaran Wartop (Wayang Karakter Tokoh Pablawan) untuk. Menumbubkan Jiwa Nasionalisme Mahasiswa IKIP Budi Utomo Malang

Ibrahim, Reyzal. (2011). Model Pengembangan ADDIE. [Online] Tersedia: http://jurnalpdf. info/pdf/model-pengembangan-addie.html

Levstik, Linda S and Keith C. (1997). Doing History. New Jersey (USA): Lawrence Publisher

Peraturan Pemerintah Nomor 32 Tahun 2013 tentang Perubahan atas Peraturan Pemerintah
Nomor 19 Tahun 2005 tentang Standar Nasional Pendidikan. (2013). Jakarta: Kementrian Pendidikan Nasional

Setyosari, Punaji. (2010). Metode Penelitian Pendidikan dan Pengembangannya. Jakarta: Kencana. 